\title{
IMPACT OF UNCERTAINTY ON EUROPEAN MARKET INDICES QUANTILE REGRESSION APPROACH
}

\author{
Mária Bohdalová, ${ }^{1}$ Michal Greguš ${ }^{2}$
}

\begin{abstract}
Contemporary Europe needs to make important collective economic and foreign-policy decisions. Many authors argue that uncertainty has influence on the markets' behavior. Therefore, we have decided to analyze the impact of the uncertainty on the returns and the volatility of two major European market indices Germany (DAX) and the U.K. (FTSE 100) across selected quantiles. We present results for the time-period from January 3, 2000 to December 30, 2016. As influential factors, we consider the Economic policy uncertainty (EPU) indices for Europe, the United Kingdom, Brexit and low prices of the crude oil. In our paper, we have found an asymmetric dependence of the analyzed market indices on the selected factors. EPU Brexit had no or weak impact on the analyzed data. Our conclusion shows to investors how sensitive German and English markets are to the uncertainty in Europe.
\end{abstract}

JEL Classification Numbers: C21, C40, G11; DOI: http://dx.doi.org/10.12955/cbup.v5.902

Keywords: quantile regression, uncertainty, Brexit.

\section{Introduction}

Policy uncertainty in Europe has intensified because of the Global Financial Crisis, serial crises in the Eurozone, Brexit, etc. Following the recession in 2007-2009, the uncertainty of economic policy has increased as a result of uncertainty among businesses and households about future tax, regulatory, spending, health and monetary policies. However, dominant entrepreneurs and households decreased their spending on investment, consumption and rent following the recession, which resulted in slowing down the increase in policy uncertainty. Baker et al. (2015) investigated the role of policy uncertainty, and they have developed an index of economic uncertainty (EPU) for the United States. Bloomberg gives us an opportunity to analyze economic policy uncertainty for Europe, the United Kingdom and for Brexit in indices EPUCCEUM, EPUCUK, and EPUCBREX. The construction of these indices is based on newspaper articles regarding policy uncertainty concerning economy, uncertainty and information on spending, deficit, regulation, budget, tax, policy, or the Bank of England, or the ECB. We have taken $E P U$ indices as risk factors for analyzing two major European markets - the $D A X$, Germany market and the FTSE 100, UK market. In addition to these indices, we have considered the volatility of oil prices and the volatility of the EUSTOXX European market.

In this paper, we have used a quantile regression method (Engle and Manganelli, 2004; Alexander, 2008; Birău and Antonescu, 2014; Naifar, 2016; Aymen and Mongi, 2016) to analyze the impact of uncertainty on major European market indices. Precisely, we propose a new model based on quantitative regression approach to explore how the individual mentioned risk factors affect the returns and volatility of the market index DAX and the FTSE 100. Our quantile regression model enables us to analyze the dynamics of the co-movement of the returns and volatilities through selected quantiles. Our findings give insight into the reaction of European equity markets to uncertainty and ultimately, they can help policy-makers, investors, and risk managers.

The paper is organized as follows. The next section shortly describes quantile regression and introduces our model. The section on data analysis presents analyzed data and results. The last section concludes our findings.

\section{Methodology}

The correlation coefficient measures the linear symmetric dependency between the analyzed variables. However, it cannot measure dependence between large and small movements of the analyzed financial time series. Therefore, we have used a quantile regression approach to analyze this complex dependence. Quantile regression gives us information not only about the average dependence in comparison to ordinary least square regression method (OLS) but we can learn also about lower and upper tail dependence (Koenker and Bassett, 1978; Alexander, 2008; McMillen, 2013; Mensi et al., 2014; Aymen and Mongi, 2016). The quantile regression model gives a set of regression curves that

\footnotetext{
${ }^{1}$ Comenius University in Bratislava,Slovakia, Maria.Bohdalova@fm.uniba.sk

${ }^{2}$ Comenius University in Bratislava,Slovakia, Michal.Gregus@fm.uniba.sk
} 
differ across selected quantiles $q$ of the conditional distribution of the endogenous variable. QR is a distribution-free technique to estimate the effect of an endogenous variable on the quantiles of the response distribution. Its main advantage comparing to OLS regression is the flexibility in data modeling with different conditional distributions.The $q$-th conditional quantile function of the dependent variable $Y$ on independent variable $X$ (when variables $X$ and $\underline{Y}$ are linearly dependent) is given as (Mensi et al., 2014)

$$
Q_{Y}(q \mid X)=\inf \left\{b \mid F_{Y}(b \mid X) \geq q\right\}=\sum_{i} \beta_{i}(q) X_{i}=X^{T} \beta(q)
$$

where $F_{Y}(b \mid X)$ is the conditional distribution function of $Y$ for given $X . \beta(q)$ is a vector of the quantile regression coefficients that determines the relationship between variable $X$ and the $q$-th conditional quantile of $Y, 0<q<1$.

$$
\hat{\beta}(q)=\arg \min \sum_{t=1}^{T}\left(q-1_{Y_{t} \leq X_{t}^{T} \beta(q)}\right)\left|Y_{t}-X_{t}^{T} \beta(q)\right|,
$$

where

$$
1_{Y_{t} \leq X_{t}^{T} \beta(q)}=\left\{\begin{array}{ccc}
1 & \text { if } & Y_{t} \leq X_{t}^{T} \beta(q) \\
0 & \text { otherwise }
\end{array} .\right.
$$

The dependence structure of $Y$ is determined by the values of $\beta(q)$. This structure is either constant when the values of $\beta(q)$ are the same for each quantile $q$ or monotonically decreasing/increasing,

when the values of $\beta(q)$ decrease/increase for the increasing quantile $q$ or asymmetric/symmetric when the values of $\beta(q)$ are dissimilar/similar for lower and upper tail of the distribution of $X$ (Mensi et al., 2014).

To determine the impact of the uncertainty on the selected stock markets log returns (log returns are given by formula: $r_{t}=\ln P_{t} / \ln P_{t-1}, t=1, \ldots, T$, excluding account dividends) or volatilities based on EWMA model (Alexander, 2008), we consider the following multivariable QR model.

$$
Q_{Y}(q \mid \boldsymbol{X})=\boldsymbol{X}^{T} \boldsymbol{\beta}(q),
$$

where

$\boldsymbol{\beta}(q)=\left(\alpha(q), \beta_{1}(q), \ldots, \beta_{6}(q)\right)$,

$Y$ are either log returns or volatility of the DAX stock index and

$\boldsymbol{X}^{T}=($ UKVolatility, COVolatility, SXXEVolatility, EPUCBREX, EPUCCEUM, EPUUK)

or $Y$ are either log returns or volatility of the FTSE 100 stock index and

$\boldsymbol{X}^{T}=($ DAXVolatility, COVolatility, SXXEVolatility, EPUCBREX, EPUCCEUM, EPUUK)

when EWMA model volatility is used for the DAX, the FTSE100, the SSXE stock index and Crude oil close prices.

\section{Data analysis}

Our empirical analysis examines impact uncertainty on major European markets represented by the $D A X$ and the FTSE 100 stock market index. The DAX index includes 30 major issues traded on the German stock exchange in Frankfurt. The United Kingdom index FTSE 100 takes into account the value growth of the 100 largest market capitalization shares. The weighting of individual companies is determined by the "free float value" (market value of the freely traded number of shares) for both indices. Risk factors include the volatility of the European stock market represented by the EUSTOXX 50 stock (SXXE), volatilities of the DAX, the FTSE 100 and crude oil closing prices $(C O)$. Then we have used the European economic uncertainty index EPUCCEUM, the U.K. economic uncertainty index EPUCUK and the economic uncertainty index due to Brexit EPUCBREX.The data were collected from a Bloomberg data provider, monthly from January 2000 to December 2016. The currency used is Euro. The analyzed time series are shown in Figure 1. As we can see, the evolution of the DAX and the FTSE 100 is similar during the analysed period (Fig1,left). The gauge of economic 
policy uncertainty in the United Kingdom has quadrupled in 2016. The uncertainty gauge for Europe also reached a record high (Figure 1, right).

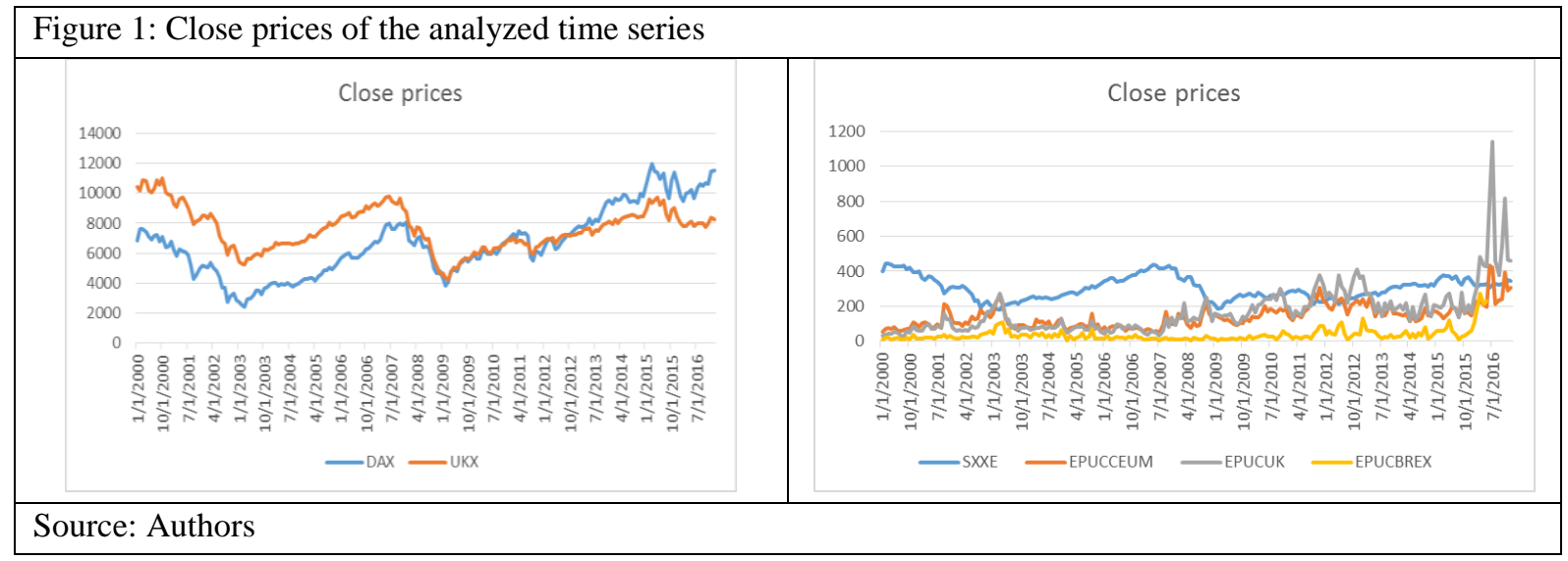

We present results obtained using IBM SPSS software. We have decided to estimate the quantile regression coefficients across nine quantiles $q=\{0.01,0.05,0.1,0.25,0.5,0.75,0.90,0.95,0.99\}$.

Table 1 provides the results for the log returns of the Germany market index $D A X$. Table 2 gives results for the $E W M A$ volatility of the German market index $D A X$. Similarly, Table 3 gives results for the log returns of the U.K. market FTSE 100. Table 4 shows the results for the EWMA volatility of the U.K. market index FTSE 100. Tables 1 and 3 present the estimation of the quantile regression coefficients for model (4). Tables 2 and 4 give the estimation of the quantile regression coefficient for the market index volatility, see model (4). We have denoted by one asterisk "*” the statistical significance of the QR coefficients at the 5\% level and by two asterisks “**” the statistical significance at the $10 \%$ level.We have found a significant negative effect of the FTSE 100 volatility on the index $D A X \log$ returns only for quantiles $0.01,0.1$ and 0.25 . Slightly lower dependence is given by the $25 \%$ quantile, then the $1 \%$ quantile follows, and the strongest dependence is shown by the $10 \%$ quantile. The impact of crude oil volatility is positive and significant only for the $10 \%$ quantile. The volatility of the EUSTOXX 50 has significant negative influence on the DAX log returns for quantiles from 0.01 to 0.25 . However, for quantiles from 0.75 to 0.99 , the volatility of the EUSTOXX 50 has a significant positive influence. Brexit influences positively only lower quantiles from 0.01 to 0.1 . The Economic policy uncertainty index for Europe has significant negative influence from $1 \%$ to $50 \%$ quantiles and slightly positive influence from $90 \%$ to $99 \%$ quantiles. Only the high quartile is without influence of the EPUCCEUM. Economic policy uncertainty index for the U.K. shows positive influence on the lower quartile and the median and negative influence for $95 \%$ quantile. The other quantiles do not show significant dependence (see Table 1).

\begin{tabular}{|c|c|c|c|c|c|c|c|c|c|}
\hline & 0.01 & 0.05 & 0.10 & 0.25 & 0.50 & 0.75 & 0.90 & 0.95 & 0.99 \\
\hline Intercept & -0.007 & 0.001 & 0.000 & 0.002 & 0.001 & 0.000 & -0.001 & 0.000 & -0.003 \\
\hline $\operatorname{Pr}>|t|$ & $0.003^{*}$ & 0.649 & 0.944 & $0.001^{*}$ & 0.145 & 0.860 & 0.248 & 0.945 & 0.115 \\
\hline UKXVol & -0.058 & -0.022 & -0.040 & -0.015 & -0.004 & -0.006 & -0.015 & 0.013 & -0.021 \\
\hline $\operatorname{Pr}>|t|$ & $0.061^{* *}$ & 0.235 & $0.004^{*}$ & $0.083^{* *}$ & 0.445 & 0.449 & 0.177 & 0.479 & 0.392 \\
\hline COVol & 0.013 & -0.003 & 0.008 & -0.002 & 0.000 & 0.001 & 0.003 & -0.002 & 0.006 \\
\hline $\operatorname{Pr}>|t|$ & 0.148 & 0.577 & $0.056^{* *}$ & 0.503 & 0.862 & 0.652 & 0.261 & 0.735 & 0.356 \\
\hline SXXEVol & -0.112 & -0.096 & -0.059 & -0.032 & 0.004 & 0.044 & 0.094 & 0.101 & 0.200 \\
\hline $\operatorname{Pr}>|t|$ & $0.000^{*}$ & $0.000^{*}$ & $0.000^{*}$ & $0.000^{*}$ & 0.393 & $0.000^{*}$ & $0.000^{*}$ & $0.000^{*}$ & $0.000^{*}$ \\
\hline EPUCBREX & 0.002 & 0.001 & 0.001 & 0.000 & 0.000 & 0.000 & 0.000 & 0.000 & 0.000 \\
\hline $\operatorname{Pr}>|\mathbf{t}|$ & $0.000^{*}$ & $0.000^{*}$ & $0.000^{*}$ & 0.885 & 0.451 & 0.243 & 0.216 & 0.344 & 0.352 \\
\hline EPUCCEUM & -0.003 & -0.002 & -0.002 & -0.001 & -0.001 & 0.000 & 0.001 & 0.001 & 0.001 \\
\hline Pr $>|\mathbf{t}|$ & $0.000^{*}$ & $0.000^{*}$ & $0.000^{*}$ & $0.000^{*}$ & $0.000^{*}$ & 0.110 & $0.014^{*}$ & $0.002^{*}$ & $0.052^{* *}$ \\
\hline EPUCUK & 0.000 & 0.000 & 0.000 & 0.0002 & 0.0001 & 0.000 & 0.000 & -0.0005 & 0.000 \\
\hline $\operatorname{Pr}>|\mathbf{t}|$ & 0.570 & 0.421 & 0.119 & $0.020^{*}$ & $0.012^{*}$ & 0.258 & 0.195 & $0.010^{*}$ & 0.100 \\
\hline
\end{tabular}


The impact of crude oil prices volatility on the $D A X$ volatility is systematic with positive influence on the upper quartile and then it varies to negative influence. Volatility of the FTSE 100 does not impact the $D A X$ volatility only for the $5 \%$ quantile. Otherwise, it has weak negative fluctuating impact on the median. Starting with the upper quartile, the positive impact grows. The impact of the volatility of the EUROSTOXX 50 is significant positive with the strongest impact on the median. EPUCBREX shows lower negative influence only for the $95 \%$ and $99 \%$ quantile. EPUCCEUM has a very small positive significant effect only for the lower quartile and the $99 \%$ quantile. EPUUK has no impact from the lower to the upper quartile. The dependence for the other quantiles is lower and significant (see Tab2).

\begin{tabular}{|c|c|c|c|c|c|c|c|c|c|}
\hline & 0.01 & $\overline{0.05}$ & 0.1 & 0.25 & 0.5 & 0.75 & 0.9 & 0.95 & 0.99 \\
\hline Intercept & 0.012 & 0.004 & -0.004 & -0.010 & -0.005 & 0.003 & 0.005 & 0.006 & -0.015 \\
\hline $\operatorname{Pr}>|\mathbf{t}|$ & $0.000^{*}$ & $0.000^{*}$ & $0.000^{*}$ & $0.000^{*}$ & $0.000^{*}$ & $0.004^{*}$ & $0.000^{*}$ & $0.000^{*}$ & $0.000^{*}$ \\
\hline COVol & 0.084 & 0.101 & 0.109 & 0.098 & 0.068 & 0.029 & -0.029 & -0.051 & 0.082 \\
\hline $\operatorname{Pr}>|\mathbf{t}|$ & $0.000^{*}$ & $0.000^{*}$ & $0.000^{*}$ & $0.000^{*}$ & $0.000^{*}$ & $0.000^{*}$ & $0.000^{*}$ & $0.000^{*}$ & $0.000^{*}$ \\
\hline UKXVol & -0.091 & -0.001 & -0.062 & -0.140 & -0.087 & 0.205 & 0.474 & 0.653 & 0.328 \\
\hline $\operatorname{Pr}>|\mathbf{t}|$ & $0.000^{*}$ & 0.914 & $0.000^{*}$ & $0.000^{*}$ & $0.000^{*}$ & $0.000^{*}$ & $0.000^{*}$ & $0.000^{*}$ & $0.000^{*}$ \\
\hline SXXEVol & 0.743 & 0.715 & 0.847 & 1.045 & 1.081 & 0.910 & 0.856 & 0.758 & 1.079 \\
\hline $\operatorname{Pr}>|\mathbf{t}|$ & $0.000^{*}$ & $0.000^{*}$ & $0.000^{*}$ & $0.000^{*}$ & $0.000^{*}$ & $0.000^{*}$ & $0.000^{*}$ & $0.000^{*}$ & $0.000^{*}$ \\
\hline EPUCBREX & 0.000 & 0.000 & -0.0001 & 0.000 & 0.000 & 0.000 & 0.000 & 0.000 & -0.003 \\
\hline $\operatorname{Pr}>|\mathbf{t}|$ & 0.798 & $0.000^{*}$ & 0.386 & 0.776 & 0.937 & 0.353 & 0.144 & $0.035^{*}$ & $0.000^{*}$ \\
\hline EPUCCEUM & -0.001 & -0.001 & 0.000 & 0.001 & -0.001 & 0.001 & 0.000 & 0.000 & 0.003 \\
\hline $\operatorname{Pr}>|\mathbf{t}|$ & $0.000^{*}$ & $0.000^{*}$ & 0.315 & $0.002^{*}$ & $0.003^{*}$ & $0.005^{*}$ & 0.794 & 0.902 & $0.000^{*}$ \\
\hline EPUCUK & 0.001 & 0.001 & 0.000 & 0.000 & 0.000 & 0.000 & -0.002 & -0.001 & 0.002 \\
\hline $\operatorname{Pr}>|\mathbf{t}|$ & $0.000^{*}$ & $0.000^{*}$ & $0.038^{*}$ & 0.184 & 0.581 & 0.150 & $0.000^{*}$ & $0.000^{*}$ & $0.000^{*}$ \\
\hline
\end{tabular}

Table 3: The estimation of the quantile regression coefficients for the FTSE 100 returns

\begin{tabular}{|c|c|c|c|c|c|c|c|c|c|}
\hline & 0.01 & 0.05 & 0.1 & 0.25 & 0.5 & 0.75 & 0.9 & 0.95 & 0.99 \\
\hline Intercept & -0.003 & 0.001 & 0.002 & 0.001 & 0.000 & -0.001 & 0.000 & -0.002 & -0.002 \\
\hline $\operatorname{Pr}>|t|$ & 0.228 & 0.181 & $0.005^{*}$ & $0.092^{* *}$ & 0.134 & $0.048^{*}$ & 0.532 & $0.070^{* *}$ & 0.227 \\
\hline DAXVol & 0.062 & 0.056 & 0.019 & -0.011 & -0.005 & -0.002 & 0.002 & -0.002 & -0.011 \\
\hline $\operatorname{Pr}>|t|$ & $0.031^{*}$ & $0.000^{*}$ & $0.012^{*}$ & $0.045^{*}$ & 0.220 & 0.713 & 0.820 & 0.836 & 0.550 \\
\hline COVol & 0.000 & -0.009 & -0.009 & -0.001 & -0.001 & 0.005 & 0.003 & 0.004 & 0.006 \\
\hline $\operatorname{Pr}>|\mathbf{t}|$ & 0.991 & $0.010^{*}$ & $0.000^{*}$ & 0.484 & 0.459 & $0.000^{*}$ & 0.202 & 0.193 & 0.240 \\
\hline SXXEVol & -0.215 & -0.154 & -0.086 & -0.022 & 0.006 & 0.032 & 0.064 & 0.103 & 0.160 \\
\hline $\operatorname{Pr}>|\mathbf{t}|$ & $0.000^{*}$ & $0.000^{*}$ & $0.000^{*}$ & $0.000^{*}$ & 0.213 & $0.000^{*}$ & $0.000^{*}$ & $0.000^{*}$ & $0.000^{*}$ \\
\hline EPUCBREX & 0.002 & 0.000 & 0.000 & 0.000 & 0.000 & 0.000 & 0.000 & 0.000 & 0.000 \\
\hline $\operatorname{Pr}>|t|$ & $0.000^{*}$ & $0.000^{*}$ & $0.054^{* *}$ & 0.735 & 0.152 & $0.052^{* *}$ & 0.112 & 0.171 & 0.256 \\
\hline EPUCCEUM & -0.002 & -0.002 & -0.001 & -0.001 & 0.000 & 0.000 & 0.001 & 0.001 & 0.001 \\
\hline $\operatorname{Pr}>|t|$ & $0.000^{*}$ & $0.000^{*}$ & $0.000^{*}$ & $0.000^{*}$ & $0.022^{*}$ & $0.032^{*}$ & $0.000^{*}$ & $0.000^{*}$ & $0.002^{*}$ \\
\hline EPUCUK & 0.000 & 0.000 & 0.000 & 0.000 & 0.000 & 0.000 & 0.000 & 0.000 & 0.000 \\
\hline $\operatorname{Pr}>|\mathbf{t}|$ & 0.662 & 0.586 & 0.803 & 0.385 & 0.176 & 0.820 & $0.060^{* *}$ & $0.074^{* *}$ & 0.310 \\
\hline
\end{tabular}

The FTSE $100 \log$ returns are significantly positively influenced by the DAX volatility only for the lower quantiles until the lower quartile with a decreasing impact. The effect of crude oil volatility is negative and the same for the $5 \%$ and $10 \%$ quantile, and it has a positive impact for the upper quartile. The volatility of the EUSTOXX 50 has significant negative decreasing influence on the FTSE $100 \log$ returns for the quantiles from 0.01 to 0.25 . However, for quantiles from 0.75 to 0.99 , the volatility of the EUSTOXX 50 has significant increasing positive influence. Brexit influences positively only the lower quantiles from 0.01 to 0.1 . The economic policy uncertainty index for Europe has significant negative decreasing influence from $1 \%$ to $25 \%$ quantiles and a slightly positive increasing influence from $50 \%$ to $99 \%$ quantiles. The Economic policy uncertainty index for the U.K. shows a lower positive influence only for the $90 \%$ and $95 \%$ quantile at a significance level of $90 \%$ (see Table 3).The volatility of the FTSE 100 is under systematic influence of the DAX volatility. This dependence is positive and smoothly decreasing across the analyzed quantiles to the upper quartile, and then it varies to negative decreasing influence. The impact of the volatility of crude oil prices on the FTSE 100 volatility is systematic positive to $95 \%$. The impact of the volatility of the EUROSTOXX 50 is 
significant positive across all quantiles with the strongest impact at 99\%. EPUCBREX shows a lower positive influence only from the $1 \%$ quantile to the $25 \%$ quantile. EPUCCEUM has a very small positive significant effect only for the $1 \%$ and $5 \%$ quantile and the $75 \%$ and $99 \%$ quantile. EPUCUK has a weak impact from the lower to upper quantiles (see Table 4).

\begin{tabular}{|llllllllll|}
\hline \multicolumn{7}{|l}{ Table 4: The estimation of the quantile regression coefficients for the FTSE 100 volatility } \\
\hline & $\mathbf{0 . 0 1}$ & $\mathbf{0 . 0 5}$ & $\mathbf{0 . 1}$ & $\mathbf{0 . 2 5}$ & $\mathbf{0 . 5}$ & $\mathbf{0 . 7 5}$ & $\mathbf{0 . 9}$ & $\mathbf{0 . 9 5}$ & $\mathbf{0 . 9 9}$ \\
\hline Intercept & -0.016 & -0.014 & -0.014 & -0.018 & -0.023 & -0.019 & -0.004 & 0.006 & 0.014 \\
Pr $>|\mathbf{t}|$ & $0.000^{*}$ & $0.000^{*}$ & $0.000^{*}$ & $0.000^{*}$ & $0.000^{*}$ & $0.000^{*}$ & $0.000^{*}$ & $0.000^{*}$ & $0.000^{*}$ \\
\hline DAXVol & 0.447 & 0.410 & 0.333 & 0.178 & 0.051 & -0.134 & -0.197 & -0.273 & -0.384 \\
Pr $>|\mathbf{t}|$ & $0.000^{*}$ & $0.000^{*}$ & $0.000^{*}$ & $0.000^{*}$ & $0.000^{*}$ & $0.000^{*}$ & $0.000^{*}$ & $0.000^{*}$ & $0.000^{*}$ \\
\hline COVol & 0.095 & 0.113 & 0.107 & 0.119 & 0.133 & 0.106 & 0.033 & -0.003 & -0.033 \\
Pr $>|\mathbf{t}|$ & $0.000^{*}$ & $0.000^{*}$ & $0.000^{*}$ & $0.000^{*}$ & $0.000^{*}$ & $0.000^{*}$ & $0.000^{*}$ & 0.232 & $0.000^{*}$ \\
\hline SXXEVol & 0.171 & 0.204 & 0.342 & 0.590 & 0.815 & 1.114 & 1.281 & 1.398 & 1.578 \\
Pr $>|\mathbf{t}|$ & $0.000^{*}$ & $0.000^{*}$ & $0.000^{*}$ & $0.000^{*}$ & $0.000^{*}$ & $0.000^{*}$ & $0.000^{*}$ & $0.000^{*}$ & $0.000^{*}$ \\
\hline EPUCBREX & 0.001 & 0.002 & 0.002 & 0.001 & 0.000 & 0.000 & 0.000 & 0.000 & 0.000 \\
Pr $>|\mathbf{t}|$ & $0.000^{*}$ & $0.000^{*}$ & $0.000^{*}$ & $0.000^{*}$ & 0.702 & 0.828 & 0.501 & 0.376 & 0.133 \\
\hline EPUCCEUM & 0.000 & 0.001 & 0.000 & 0.000 & 0.000 & 0.001 & 0.000 & 0.001 & 0.003 \\
Pr $>|\mathbf{t}|$ & $0.006^{*}$ & $0.000^{*}$ & 0.259 & 0.595 & $0.079^{* *}$ & $0.000^{*}$ & 0.968 & $0.002^{*}$ & $0.000^{*}$ \\
\hline EPUCUK & -0.001 & -0.002 & -0.001 & 0.000 & 0.000 & 0.000 & 0.000 & 0.000 & -0.001 \\
\hline Pr $>|\mathbf{t}|$ & $0.000^{*}$ & $0.000^{*}$ & $0.000^{*}$ & $0.000^{*}$ & $0.001^{*}$ & $0.063^{* *}$ & $0.000^{*}$ & $0.003^{*}$ & $0.000^{*}$ \\
\hline Source: Authors & & & & & & & & & \\
\hline
\end{tabular}

\section{Conclusion}

Our paper has analyzed the impact of economic uncertainty and selected volatilities on the German and U.K. stock markets across selected quantiles of the return distributions. Empirical results presented in this paper indicate an asymmetric dependence between the EU stock markets and all considered influential factors for the period from January 2000 to December 2016 . We have found that the volatility of oil prices shows an asymmetric dependence with the U.K. and German markets returns in bullish and bearish markets conditions. The U.K. market volatility is independent from the oil price during the bear market conditions. The EUROSTOXX volatility co-move positively with the DAX and FTSE 100 volatilities, and it has a negative decreasing impact when the market is bearish. Finally, the economic policy uncertainty Brexit index had a weak influence on the U.K. and German stock markets mainly for the quantiles of the lower quartile. Otherwise, it did not have any influence. Our findings can be helpful to international investors because it shows them how sensitive the German and English markets are to the uncertainty in Europe.

\section{References}

Alexander, C. (2008). Market Risk Analysis. Chichester. John Wiley \& Soons.

Aymen, B. R., Mongi, A. (2016). Financial market interdependencies: A quantile regression analysis of volatility spillover. Research in International Business and Finance, 36, 140-157. doi:10.1016/j.ribaf.2015.09.022,NBER WORKING PAPER SERIES

Baker, S. R, Bloom, N., Davis, S. J. (October 2015). Measuring Economic Policy Uncertainty. Working Paper 21633, National Bureau of Economic Research, Cambridge. http://www.nber.org/papers/w21633

Birău, R., Antonescu, M. (2014). Investigating Long-term Dynamic Causal Linkages between Hungarian and Romanian Stock Markets. Procedia Economics and Finance, 16, 669-679. doi:10.1016/S2212-5671(14)00855-7

Engle, R.F., Manganelli, S. (2004). CAViaR: conditional autoregressive value at risk by regression quantiles. In: Journal of Business and Economic Statistics 22, 367-381.

Koenker, R., Bassett, G. (1978). Regression quantiles. Econometrica, 46, 33-50.

McMillen, D. P. (2013). Quantile Regression for Spatial Data. Springer

Mensi, W., Hammoudeh, S., Reboredo, J. C., Nguyen, D. K. (2014). Do global factors impact BRICS stock markets? A quantile regression approach. In: Emerging Markets Review, Vol. 19, June 2014, 1-17, doi:10.1016/j.ememar.2014.04.002

Naifar, N. (2016). Do global risk factors and macroeconomic conditions affect global Islamic index dynamics? A quantile regression approach. In: The quaterly Review of Economics and Finance 61, 29-39. [Online]. Available at: http://dx.doi.org/10.1016/j.qref.2015.10.004 [Accessed: October, 15, 2016] 